\title{
PREMENSTRUAL SYNDROME: PREVALENCE IN STUDENTS OF THE UNIVERSITY OF CALABAR, NIGERIA
}

\author{
${ }^{1 *}$ ANTAI A.B, ${ }^{3}$ UDEZI, A.W, ${ }^{2}$ EKANEM, E.E. ${ }^{1}$ OKON, U.J AND ${ }^{4}$ UMOIYOHO A.U. \\ Departments of ${ }^{1}$ Physiology and ${ }^{2}$ Department of Obstetrics and Gynaecology, University of Calabar, \\ Department of ${ }^{3}$ Clinical Pharmacy and ${ }^{4}$ Obstetrics and Gynaecoclogy, University of Uyo, Uyo Nigeria.
}

The prevalence and frequency of symptoms of premenstrual syndrome (PMS) was assessed in female undergraduate students of the University of Calabar. A survey of a consecutive sample of 200 nulliparous subjects aged between 16 and 31 years revealed that $85.5 \%$ of them regularly experienced symptoms suggestive of PMS. The commonest symptoms were lower abdominal pain, pimples/puffy face, tender/painfully engorged breast and depression/tension representing 86\%, 67\% $63 \%$, and $55 \%$ respectively. The least frequent symptoms were back ache and common cold which was seen in $14 \%$ and $11 \%$ of the subjects respectively. $42 \%$ of the subjects complained of severe abdominal pain. This group had depression/tension as the most frequently occurring symptom (87\%), while pimples/ puffy face was most frequently seen in those with mild, moderate and no abdominal discomfort.. There was an association between severity of abdominal discomfort and symptoms experienced by subjects $(p<0.01)$. Similarly, severity of abdominal discomfort was associated with mean body weight of subjects $(P<0.02)$ but not with body temperature.

Key words: premenstrual syndrome, abdominal discomfort, prevalence depression, Calabar

Author for correspondence: e-mail: eduanwana@yahoo.com

\section{INTRODUCTION}

Premenstrual syndrome (PMS) is a common disorder of young and middle-aged women characterized by cyclic occurrence in the luteal phase of the menstrual cycle of a combination of distressing physical, psychological and behavioral changes of sufficient severity to result in deterioration of inter- personal relationships and / or interference with normal activities; which remit upon onset or immediately after menstruation (Reid, 1993; Wyatt et al, 1999, 2001; Frackiewitz and Shiovitz, 2001).

About seven to four days, prior to, and in some cases, into menstruation, some females have clearly defined manifestation of certain symptoms with both somatic and psychological components. Such symptoms include mood swings, tension, anger mastalgia, abdominal discomfort, irritability, headache, bloating, and increased appetite with food cravings. Others are, lack of energy, feelings of being unable to cope, a sense of loss of control and exacerbation of chronic illnesses such as asthma,, allergies epilepsy or migraine (Pray, 1998; Wyatt et al, 1999;). Although these symptoms are apparently unrelated, the common factor is their cyclic occurrence with a consistent and predictable relationship to menstruation in each cycle.

PMS has been reported in $40-95 \%$ of menstruating women (Frackiewicz and Shiovitz, 2001; Pray, 1998). For most of these women, PMS is a minor problem (Chuong and Dawson, 1994) while some even report positive features such as 
increased industriousness, energy, creativity and sexual interests (Choi and McKeown, 1997; Pray, 1998). The syndrome may begin at any phase of reproductive life but is more commonly reported by women in the later reproductive years and in those with more years of natural menstrual cycles (Reid, 1993). The aetiology of the syndrome is controversial, and has been extensively reviewed (Wyatt et al, 1999; Frackiewicz and Shiovitz, 2001). These include, a combination of low zinc and copper retention (Chuong and Dawson, 1994), abnormal serotonin function (Eriksson,1999) deficiency of progesterone, some neurotransmitters, nutrients such as vitamin E, B vitamins, calcium, linolenic acid, magnesium manganese, etc, (Wyatt et al, 1999; 2001).

Treatment of PMS aims to relief symptoms and restore function, and often requires a combination of lifestyle modifications and drug therapy (Pray, 1998). Frequently used remedies include oral contraceptives, serotonin reuptake inhibitors, antidepressants, anxiolytics, progesterone, diuretics, vitamins $\mathrm{B} 6$ and $\mathrm{E}$, calcium magnesium herbal products, exercise, eating smaller, more frequent meals and reducing consumption of sugar, salt, caffeine alcohol, etc (Frackiewicz and Shiovitz, 2001). There is a genetic predisposition to PMS (Condon,1993), and major life events/daily stressors such as marriage, divorce, and caring for children influence the course of the syndrome (Woods, Most and Longnecker, 1985).

More recently, PMS has been referred to as late luteal dysphonic disorder and is included as a diagnosis in the revised third edition of the Diagnostic and Statistical manual of Mental Disorders, published by the American Psychiatric Association (Parker, 1994). Patients who suffer from five or more symptoms including one mood disorder are classified as having premenstrual dysphoric disorder (PMDD), a more severe form of the disease that is associated with such severe symptoms that the lives of the sufferers are completely disrupted (Reid, 1993; Yonkers, 1997; Wyatt et al, 2001). PMDD occurs in 3-9\% of women. More serious disorders may mimic it and there are no biochemical tests that confirm clinical suspicions (Pray, 1998).

Consequently, the diagnosis is usually made on the basis of a patient -completed daily symptom calendar and the exclusion of other medical disorders (Pray, 1998; Frackiewicz and Shiovitz, 2001). This study seeks to establish the prevalence of the syndrome in undergraduate students of the University of Calabar. It will also document the pattern and severity of the symptoms in this population.

\section{METHOD}

A consecutive sample of 200 female students residing in the female hostel of the University of Calabar, a university located in the south eastern part of Nigeria, was selected for this study. PMS was diagnosed using standard criteria (WHO International Classification of Diseases, 1996). The inclusion criteria were that the subjects should have experienced on a regular basis both somatic and psychological symptoms which occur in the luteal phase, peak before menses, remit during or shortly after the onset of menses, with a symptom-free period before ovulation every month. Those who reported dysmenorrhoea, menstrual distress (occurrence of PMS symptoms at the follicular phase) and use of intrauterine device and or medications were excluded from the study. In addition, our subjects were nulliparous. A self-administered questionnaire was developed. Content validity was built into the questionnaire by including known PMS symptoms obtained from literature evidence and an initial group discussion with some female students. The group discussion revealed that lower abdominal discomfort appears to be very common.

Symptoms of abdominal pain were divided into mild (present but does not interfere with activities); moderate (present and interferes with activities but not disabling, other people recognise it); severe, (disabling, efficiency of performing daily tasks reduced) on at least one day of the seven days of the premenstruum, and must have been occurring in previous cycles. 
African Journal of Biomedical Research 2004 (Vol. 7) / Antai, Udezi, Ekanem, Okon and Umoiyoho

The questionnaire was given to each subject to indicate if her experience of abdominal discomfort during the premenstruum is mild, moderate, severe or totally absent. Responders were also to tick the other symptoms of PMS which they have during their premenstruum. Columns were also provided for demographic data.

Forty subjects, of which 10 each had mild, moderate, severe or no abdominal discomfort during their premenstruum were selected for further study. All forty girls were chosen on the basis that they have a normal 28-day menstrual cycle. They were taught how to use an oral clinical thermometer and a Camry bathroom scale (model BR-9010). Basal body temperatures were taken between 6 and 8a.m. while awake but before getting out of bed. Body weight was measured in the morning after emptying the bladder, before breakfast, with only light clothing on. A student carried out each measurement thrice. The means of the readings were calculated daily throughout the duration of the premenstruum for each subject.

Table 1

Prevalence of PMS symptoms with severity of abdominal discomfort

\begin{tabular}{llllll}
\hline PMS Symptoms & $\begin{array}{l}\text { Mild } \\
\text { abdominal } \\
\text { discomfort } \\
\mathbf{( \% )} \\
(\mathbf{n = 6 1 )}\end{array}$ & $\begin{array}{l}\text { Moderate } \\
\text { abdominal } \\
\text { discomfort } \\
\mathbf{( \% )} \\
\mathbf{( n = 6 8 )}\end{array}$ & $\begin{array}{l}\text { Severe } \\
\text { abdominal } \\
\text { discomfort } \\
\mathbf{( \% )} \\
(\mathbf{n = 4 2 )}\end{array}$ & $\begin{array}{l}\text { No } \\
\text { abdominal } \\
\text { discomfort } \\
\mathbf{( \% )} \\
(\mathbf{n = 2 9 )}\end{array}$ & $\begin{array}{l}\text { Total (\%) } \\
\mathbf{N = 2 0 0}\end{array}$ \\
\hline $\begin{array}{l}\text { Lower abdominal } \\
\text { discomfort }\end{array}$ & $61(100.0)$ & $68(100.0)$ & $42(100.0)$ & $0(0.0)$ & $171(85.5)$ \\
\hline Pimples/puffy Face & $41(67.2)$ & $50(73.5)$ & $30(71.4)$ & $12(41.4)$ & $133(66.5)$ \\
\hline $\begin{array}{l}\text { Tender/painfully } \\
\text { Engorged breast }\end{array}$ & $43(70.5)$ & $48(70.6)$ & $28(66.7)$ & $7(24.1)$ & $126(63.0)$ \\
\hline Depression/tension & $26(42.6)$ & $33(48.5)$ & $36(85.7)$ & $14(48.3)$ & $109(54.5)$ \\
\hline Tiredness & $28(45.9)$ & $25(36.8)$ & $24(57.1)$ & $5(17.2)$ & $82(41.0)$ \\
\hline Aggression & $25(41.0)$ & $17(25.0)$ & $28(66.7)$ & $11(37.9)$ & $81(40.5)$ \\
\hline Joint/muscle pain & $20(32.8)$ & $19(27.9)$ & $15(35.7)$ & $7(24.1)$ & $61(30.5)$ \\
\hline Increased appetite & $15(24.6)$ & $22(32.4)$ & $6(14.3)$ & $7(24.1)$ & $50(25.0)$ \\
\hline Headache & $12(19.7)$ & $13(19.1)$ & $13(31.0)$ & $4(13.8)$ & $42(21.0)$ \\
\hline Weight gain & $13(21.3)$ & $14(20.6)$ & $6(14.3)$ & $7(24.1)$ & $40(20.0)$ \\
\hline Backache & $10(16.4)$ & $6(8.8)$ & $10(23.8)$ & $1(3.5)$ & $27(13.5)$ \\
\hline Common cold & $10(16.4)$ & $5(7.4)$ & $7(16.7)$ & $0(0.0)$ & $22(11.0)$ \\
\hline
\end{tabular}

The questionnaires were analyzed and the frequencies of the symptoms experienced by the subjects were calculated for each group. A chi-square test was then done. The mean temperatures and weights for each group in the second part of the variance (ANOVA) was used to find out if there was an association between the means.

\section{RESULTS}

Of the 262 students approached, 200 agreed to take part in the study representing $76.3 \%$ response rate. The age range was 16-31years with a mean of 24.3years. The mean weight was $62 \mathrm{~kg}$ with a range of $40-$ $74 \mathrm{~kg} .171(85.5 \%)$ of the population studied admitted experiencing varying degrees of symptoms consistent with PMS. Of the 13 symptoms included in the questionnaire, asthma was not reported by our subjects.

Table 1 shows the most common symptoms of subjects. study were computed. One-way analysis of 
African Journal of Biomedical Research 2004 (Vol. 7) / Antai, Udezi, Ekanem, Okon and Umoiyoho

Table 2

Mean temperatures and weights of subjects with severity of abdominal discomfort during the premensruum $(\mathrm{N}=40)$

\begin{tabular}{lllllll}
\hline & $\begin{array}{l}\text { Mild } \\
\text { Abdominal } \\
\text { Discomfort } \\
(\mathbf{n}=10)\end{array}$ & $\begin{array}{l}\text { Moderate } \\
\text { Abdominal } \\
\text { Discomfort } \\
(\mathbf{n}=10)\end{array}$ & $\begin{array}{l}\text { Severe } \\
\text { Abdominal } \\
\text { Discomfort } \\
(\mathbf{n = 1 0 )}\end{array}$ & $\begin{array}{l}\text { No } \\
\text { Abdominal } \\
\text { Discomfort } \\
(\mathbf{n}=10)\end{array}$ & P-value & Significance \\
\hline $\begin{array}{l}\text { Mean } \\
\text { temp }\end{array}$ & $37.05 \pm 0.07$ & $36.98 \pm 0.08$ & $36.99 \pm 0.09$ & $36.93 \pm 0.08$ & 0.7708 & not significant \\
$\left({ }^{\circ} \mathrm{C}\right)$ & & & & & & \\
\hline $\begin{array}{l}\text { Mean } \\
\text { weight } \\
(\mathrm{kg})\end{array}$ & $59.2 \pm 1.44$ & $55.97 \pm 2.36$ & $49.85 \pm 2.48$ & $53.31 \pm 1.78$ & 0.0199 & significant \\
\hline
\end{tabular}

About $86 \%, 67 \%, 63 \%$ and $55 \%$ of respondents reported experiencing lower abdominal pain, pimples/puffy face, tender/painfully engorged breast and depression/tension respectively. Of these, $61(36 \%)$ had severe abdominal pain, 68 (39.7\%) moderate, 42 (24.5\%) mild, while 29 $(11.7 \%)$ had no abdominal discomfort. Most of those who reported severe lower abdominal pain have depression/tension $(85.7 \%)$. Less than half of those who reported mild, moderate and no lower abdominal discomfort have depression/tension (42.6-48.3\%). Pimples/puffy face (73.5\%) and tender/painfully engorged breast (70.5\%) were the most prevalent symptoms in those reporting moderate and mild abdominal discomfort respectively.

The least symptom reported was the common cold which was $16.4 \%, 7.45,17.7 \%$ and zero in mild, moderate severe and nil abdominal discomfort groups. There appears to be an association between the severity of lower abdominal discomfort and symptoms experienced by subjects $(p=0.0017)$.

In the second part of the study; those with severe lower abdominal discomfort, compared to the other groups, did not show much variation in weight during the premenstruum (see Figure 1). There is an association between the mean weight of subjects and the severity of lower abdominal discomfort $(p=0.0199)$ as shown in table 2 . This association is absent between the mean basal body temperatures and the severity of lower abdominal discomfort.

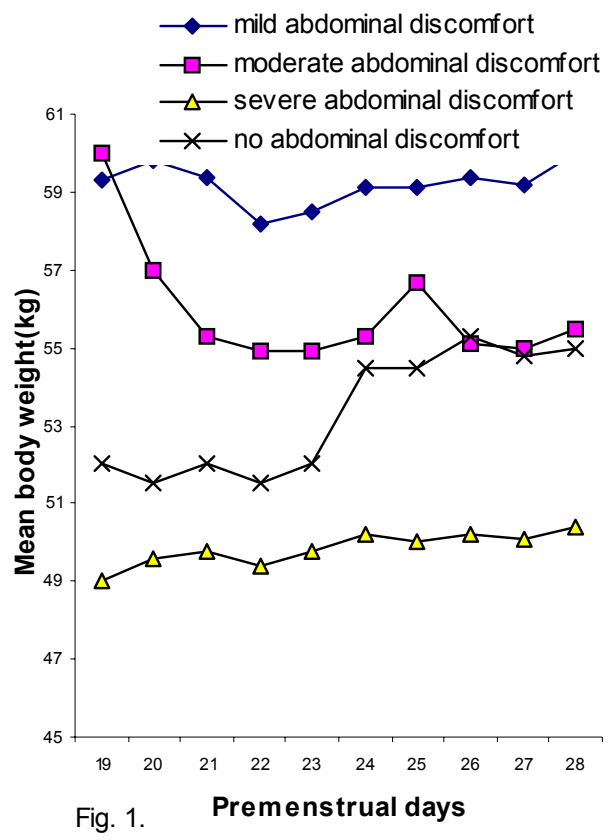

Body w eight during the premenstruum

\section{DISCUSSION}

This study shows that PMS is not uncommon in nulliparous undergraduate students of the University of Calabar. $85.5 \%$ of the subjects reported experiencing symptoms of PMS with varying degreesbreasts of intensity. Subjects in this study were aged between 16-31 years with a mean of 24.3years. Studies show that PMS symptoms may occur at any age, but onset usually begins around the mid-20s, and women who seek treatment are usually in 
their 30s (Johnson, 1987; Yonkers, 1997), which places our subjects in the high frequency group. Our result is consistent with results of similar studies. Johnson (1987) reported that $50-80 \%$ of menstruating women experience some degree of premenstrual symptoms. Similar results have been reported elsewhere (Dalton, 1984; Cleckner-Smith, Doughty and Grossman, 1998).

Using self-rating scale (Questionnaire), body temperature monitoring, and baseline weight change as the tools in the understanding of female students presenting with typical symptoms of PMS, 12 symptoms were recorded, ranging from severe abdominal pain which was most common, followed by pimples/puffy face, tender/painful breasts, depression/tension, tiredness, joint/muscle pain increased appetite, headache, weight gain, backache, and common cold, in descending order (Table1). Although PMS has been associated with increased co morbidities such as asthma, allergies, epilepsy or migraine, (Pray, 1998; Wyatt et al, 1999) asthma was not reported by any of our subjects.

Subjects were brought under sub-groups of mild, moderate and severe based on the intensity of lower abdominal discomfort experienced during the premenstruum. Those with no experience of discomfort made up the fourth group. $36 \%$ of the respondents had severe abdominal pain, $39.7 \%$ moderate, $24.5 \%$ mild, while $11.7 \%$ had no abdominal discomfort. Comparisons were made as to the influence of the various intensities of lower abdominal discomfort on the other symptoms. By our classification, the group with severe abdominal discomfort would qualify to be classified as having PMDD. The result obtained in this study for PMDD appears to be high, considering the previous reports of prevalence of PMDD of 3-9\% (Yonkers, 1997; Wyatt et al, 2001). However, it must be noted that these reports were based on the general population, and PMS symptoms tend to be more marked in younger women. Premenstrual symptoms reported as being moderate or greater in severity were found to be quite prevalent $(88 \%)$, in a sample of adolescents, the severity being greater in 16-18 year-olds
(Cleckner-Smith et al, 1998). Although abdominal discomfort topped our list of symptoms, the frequency of students reporting the psychological symptoms of depression/tension, aggression, tiredness, etc tended to increase with severity of abdominal pain and may be a psychological influence of pain on these affective symptoms. In a survey of 610 women with PMS, Dalton, (1984) showed that the commonest symptom was depression, $(73 \%)$, being highest in nulliparous women. Somatic symptoms, (pimples/puffy face, tender/painfully engorged breast) predominated the group with mild -moderate abdominal pain. In contrast, mood-related symptoms (depression, aggression) were predominant in subjects who had no abdominal discomfort.

Although more than 100 symptoms of PMS have been described (Frackiewicz and Shiovitz, 2001), the common complaints include depression, irritability, abdominal pain, bloatedness, anxiety, increased appetite, headache, etc, as in this study (Dalton 1984; Frackiewicz and Shiovitz, 2001). Somatic changes (weight gain, breast tenderness, pain/discomfort, pimples/puffy face, and bloatedness have been linked to alterations in fluid/electrolyte handling (Parker, 1994) while the psychological symptoms have been linked to aches and pains (Lockie and Geddes, 1992). This would explain the higher incidence of depression in the group with severe abdominal pain.

The course of basal body temperature has been a useful clinical quantitative tool in correlating symptoms of PMS. Body temperature was not significantly different between the groups studied. Mean body weight, on the other hand, showed a distinct correlation to the severity of abdominal pain $(P=0.0199)$. Thus those with mild-moderate abdominal discomfort had higher body weights and also reported more somatic complaints. Subjects with no abdominal discomfort had the least body weight and showed no fluctuation in weight during the premenstruum. Whether this is due to dietary habits or lesser alterations in hormone metabolism contributing to PMS remains to be seen. Of particular note is the increase in weight in subjects with severe 
abdominal discomfort. This was associated with an increased severity of somatic and psychosocial symptoms $(P<0.0019)$. The reason for this is not clear, but may not be unrelated to fluid/electrolyte retention caused by abnormal progesterone metabolism. (Rapkin et al, 1997).

In conclusion, we report a prevalence of PMS of $86 \%$ in female undergraduate students of the University of Calabar. Abdominal pain and depression were the most frequently presenting symptoms. Severity of symptoms was associated with body weight but not temperature.

\section{REFERENCES}

Choi PY, McKeown S (1997).What are young undergraduate women's qualitative experiences of the menstrual cycle? J Psychosom Obstet Gynecol; 18:259-265.

Clerkner-Smith CS, Doughty AS, Grossman JA (1998). Premenstrual symptoms: prevalence and severity in an adolescent sample. J Adolesc Health; 22:403-8.

Condon JT (1993). The premenstrual syndrome: a twin study. $\mathrm{Br} \mathrm{J}$ Psychiatry: 162:481-6.

Dalton K (1984).The premenstrual syndrome and dysmenorrhea. Urban and Schwarzenberg, Baltimore. P43.

Chuong CJ Dawson EB (1994). Zinc and copper levels in premenstrual syndrome. Fert Steril; 62:313-320.

Eriksson E (1999). Serotonin reuptake inhibitors for the treatment of premenstrual dysphoria. Int Clin Psychopharmacol; 14(suppl2):s27-31.

Frackiewicz, EJ and Shiovitz, TM. (2001). Evaluation and management of premenstrual syndrome and premenstrual dysphoric disorder. J Am Pharm Assoc; 41:437-447.

Johnson, SR (1987). The epidemiology and social impact of premenstrual symptoms. Clin Obstet Gynecol; 30:367-76.

Lockie A, Geddes N (1992). The Women's Guide to Homeopathy. Hamish-Hamilton Ltd, London. P 66-77

Parker PD (1994). Premenstrual syndrome. Am Fam Physician; 50:1309-1317.

Pray WS (1998). PMS: A disorder that is diagnosable. US Pharmacist 23(9):

Rapkin AJ, Morgan M, Goldman L Brann DW, Simone D, Mahesh VB (1997). Progesterone metabolite allopregnanolone in women with premenstrual syndrome. Obstet Gynecol; 90:709-14.

Reid, RL (1993). Psychological aspects of menstruation. In: Bruce CR, Blackwell, RE eds: Textbook of reproductive medicine. Appleton and Lange, Connecticut 409-422.

Yonkers, KA. (1997) The association between premenstrual dysphoric disorder and other mood disorders. J Clin Psychiatry 59; (suppl 15):S19-25.

World Health Organisation, International Classification of Diseases. $10^{\text {th }}$ Rev. Geneva Switzerland: WHO; 1996.

Wyatt KM, Dormick PW, Jones PW, O'Brien PMS (1999). Efficacy of vitamin B-6 in the treatment of premenstrual syndrome: systematic review. B M J 318:1375-1381.

Wyatt KM, Dimmock P, Jones $P$, Obhrai M (2001). Efficacy of progesterone and progestogens in management of premenstrual syndrome: systematic review. B M J 323:776-791.

Woods NF, Most A, Longnecker, GD (1985). Major life events, daily stressors and perimenstrual symptoms. Nurs Res: 34:2637. 